\title{
Plant breeders' rights and monopoly myths
}

\author{
William Lesser
}

Legislation may appear to provide a breeding ground for monopoly power and profit among commercial seed propagators, but farmers are canny consumers.

BERLAND and Lewontin ${ }^{1}$, in a recent Commentary article, expressed dissatisfaction with Plant Breeders' Rights (PBR) legislation which has been in existence since the early 1960 s (1970 in the United States). In essence, their position against this legislation is one of economic efficiency. They see PBR legislation as increasing the monopoly power and profits of breeders while users (farmers) are inhibited from saving seed. Seed saving is, at least in principle, not only less costly for farmers but also economically efficient compared to the annual production, sale and distribution of seed from specialized propagators. Various points support their central argument: the issue of economies of scale in farmer seed processing, the production of new seed varieties that can be promoted as such, the reliance on hybrids, and the emphasis in breeding of traits which are required by PBR legislation as opposed to other ostensibly more productive attributes. My purpose here is to show that many of these concerns which are widely shared ${ }^{2}-$ are unfounded or largely unrelated to PBR.

\section{Seed saving}

It is convenient to begin by examining the system of farmer-saved seeds in the United States and Britain. American farmers save for replanting primarily wheat, cotton and soybean seeds, which on average are replaced every other year ${ }^{3}$. In Britain about 3 per cent of the soft wheat and barley crop is withheld annually for use as seed. New seed is purchased at those intervals because (1) genetic drift reduces the production potential, and (2) breeding advances make the replacement varieties more productive. For these reasons, it is not conceivable that seed could be efficiently home-produced indefinitely. Nor are there great technical requirements for processing and retaining this seed, except for alfalfa and vegetable seeds, which are very small and difficult to handle.

This pattern is not changed by PBR laws as farmers have exemptions permitting seed saving". However, even if farmers were not permitted to retain seed, the effect on price would not be as great as implied. Suppose farmers bought new seed biennially for $\$ 35$ per bushel, supplemented by home-produced seed valued at $\$ 5$ per bushel, giving an average annual cost of $\$ 20$. Could the seed seller get $\$ 35$ per bushel every year? Possibly not, if the productive value of the seed were not great enough to allow the increased cost. The situation is little different from what a consumer would be willing to pay for a car with an expected life of 100,000 miles compared to one of 50,000 miles.

This argument does not apply to $F_{1}$ hybrid seeds, which do not reproduce true-to-type. However, one of the justifications for PBR legislation is to give private breeders incentives to produce self-pollinating varieties. Previously the only form of protection was biological, through hybrids, and research was being directed in that way, an inefficient approach for many crops.

Following the passage of PBR, an increase in private breeding in the United States was documented, most notably for soybeans ${ }^{6,7}$. Are these expenditures directed to producing seeds little distinguished from previous varieties, the socalled 'cosmetic breeding' argument ${ }^{\mathrm{s}}$ ? This argument is valid only if farmers have no alternative source of information. Such, however, is not the case. Many state and national governments test and rank popular varieties as guides to varietal selection. With such objective information it would be difficult to induce purchases with unsubstantiated sales claims. At the same time, farmers will often try a new variety in a small area before adopting it for use on a broad scale. Recognizing this, in the United States seed companies scatter demonstration plots throughout the main producing areas. With seeds a major productive input, it is not credible that farmers act naively in varietal selection. Indeed Perrin et al. ${ }^{\circ}$ have found a statistical relationship between the PBR and soybean yields in the United States.

Finally, there is no substantiation, at least in the United States, that public research bodies "will have to give up the production of commercial varieties"'. On the contrary, public breeding of commercial varieties is, and remains, an important function of state agricultural experiment stations ${ }^{6}$. What public plant breeders have done is to protect with PBR their commercial varieties and use the funds to support further research. At Cornell some $\$ 225,000$ was raised in 1985 through the commercialization of plant varieties developed in the university ${ }^{10}$. Not all varieties are protected, only those with sufficient commercial potential to justify the expense.

\section{Economics}

Several of the economic arguments offered by Berland and Lewontin are puzzling, at best. It is implied that firms purposely raise the cost to thwart entry into breeding. Yet neither evidence nor theory is presented in support. Further, the difficulty of entering breeding should not be overstated, as many firms in the United States found it possible in the era of $\mathrm{PBR}^{7}$. Statements about what is hybridized, and why, likewise defy logic and fact. Maize and sorghum were early and leading candidates for hybridization largely because the separate male and female parts make the process relatively inexpensive. Vegetables and flowers must presently be hybridized by hand, while a safe and effective male sterilization method, a necessity for the economical hybridization of wheat, has yet to be discovered. The claim that the yield potential of hybrid maize has not been documented is simply incorrect (see ref. 7).

Berland and Lewontin are correct in thinking that property rights for agricultural plants and seeds do raise public policy issues. Chief among these is assuring the collection, preservation and access to germplasm resources. Regrettably, the points they raise are not among those issues, and their implication that seed breeders are attempting to exploit their newly found property rights to extract monopoly rents from farmers tends to confuse the relevant matters, rather than illuminate them.

1. Berland, J.P. \& Lewontin. R. Nature 322, 785-788 (1986). 2. Claffey, B.A. Southern J. agr. Econ. 13, 29-37 (1981).

3. Leibenluft, R.F. in Competition in Farm Inputs: An Examination of Four Industries (US Federal Trade Commission, Office Policy Planning, 1981)

4. In Yearbook of Agricultural Statistics. Tables E3, E7, F1. F3 (Eurostat. Statistical Office of the European Committees, Brussels, 1984).

5. Lesser, W. European Intellectual Property Review 6, 172 177 (1987).

6. Butler LJ \& Marion. B.W in The Impacts of Paten Protection in the U.S. Seed Industry and Public Plant Breeding 16, 38-39 (University of Wisconsin Monograph NC-117, 1985).

7. Brim. C.A. Symp. Protection of Biotechnological Inventions, Ithaca, New York (1987).

8. Fowler. C. \& Nelson, G. Hearings before the Subcommittee on Agricultural Research and General Legislation. US Senate (1980).

9. Perrin, R.K., Hunnings, K.A. \& Ihnen, L.A. NCSU. Econ. Res. Rpt 46, 36 (1983).

10. Lesser, W. Int. Review Ind. Property and Copyright Law 18. $360-371$ (1987).

William Lesser is Associate Professor of Agricultural Economics at Cornell University, Ithaca, New York 14853, USA. 